\title{
Трансакционные издержки в управлении природными ресурсами: обзор зарубежных подходов*
}

И.П. ГЛАЗЫРИНА, доктор экономических наук, Институт природных ресурсов, экологии и криологии СО РАН, Забайкальский государственный университет, Чита. E-mail: iglazyrina@bk.ru

В статье изложены основные подходы к проблемам трансакционных издержек в управлении природными ресурсами, которые в современной эколого-экономической литературе определяются как затраты на управление социо-эколого-экономическими системами. Наиболее важным считается вопрос о том, как трансакционные издержки, их величина, характер и распределение между акторами могут влиять на достижение целей устойчивого развития стран и регионов.

Ключевые слова: трансакционные издержки, эколого-экономическая политика, институциональные решения, эффект «колеи»

Величина и характер трансакционных издержек в управлении природными ресурсами в условиях России - один из ключевых факторов, определяющих экономическую, экологическую и социальную эффективность природопользования. Анализ зарубежной научной литературы свидетельствует о том, что эта проблема актуальна для многих стран, где природопользование охватывает существенный сегмент хозяйственной деятельности [1. С. 183].

Хотя роль трансакционных издержек, в том числе в процессах природопользования, выявлена еще в работах Коуза более 50 лет назад [2], исследования последних двух десятилетий показали, что многообразие проявлений этого феномена в разных социально-экономических и природных условиях исключает возможность принятия универсальных решений в сферах повышения эффективности использования природных благ, a также неизбежно возникающих экологических последствий. По сравнению с «чистым» вариантом, описанным Коузом, в современных условиях права собственности на природные блага, связанные с острыми экологическими проблемами, часто

* Статья подготовленапри финансовой поддержке Российского научного фонда (проект 16-18-00073). 
не могут быть строго определены. Прежде всего это касается экологических функций природных систем и порождаемых ими экосистемных услуг [3, 4].

В современной научной литературе существует несколько подходов к определению понятия трансакционных издержек в сфере природопользования. Все они расширяют это понятие по сравнению с традиционным представлением о том, что это затраты, возникающие в связи с получением информации и заключением контрактов (в том числе с использованием рыночных механизмов); издержки, сопровождающие взаимоотношения экономических агентов [5]. Это обусловлено экологическими аспектами хозяйственной деятельности, связанной с использованием природных ресурсов и высоким уровнем воздействия на природные системы, «ускользающими» от экономического анализа. В статье мы будем использовать следующее определение: «Трансакционные издержки в управлении природными ресурсами - это совокупные затраты на определение, установление, поддержание, функционирование и совериенствование соответствуюших институтов (формальных и неформальных) и организации;; а также на выявление проблем, которые эти институты и организации призваны решать» [6. С. 188].

После выхода знаменитой статьи Д. Норта и Д. Уоллеса, посвященной количественной оценке трансакционного сектора в экономике США [5], были выполнены макроэкономические оценки и для других стран, в том числе для России $[7,8]$. При этом большинство зарубежных исследований анализируют данные издержки не на уровне целых стран, а в отдельных секторах природопользования. Целью этих работ далеко не всегда является количественная оценка, наиболее важным считается вопрос о том, как трансакционные издержки, их величина и характер и распределение между акторами могут влиять на достижение целей устойчивого развития стран и регионов.

\section{Трансакционые издержки, институты и «зависимость от колеи»}

Многие авторы подчеркивают критически важную роль трансакционных издержек в управлении природными ресурсами и качества соответствующих институтов; очень показательны в этом плане исследования нобелевских лауреатов Э. Остром
$[9,10]$ и О. Уильямсона [11]. Работы по этой тематике отражают разнообразие теоретических концепций и аналитических подходов, однако практически все они подчеркивают необходимость разработки механизмов для оптимизации распределения транспортных издержек с учетом региональной специфики и демонстрируют потенциальные выгоды от возможных изменений институциональной среды. Ряд работ показывают разнообразие проявлений влияния изменений среды в процедурах принятия решений [12-17] в различных секторах природопользования.

Зарубежные исследования преимущественно ориентированы на решение задач экологической устойчивости природопользования. Во многих из них речь идет о трансакционных издержках не в конкретном секторе, а в управлении «комплексными социально-экологическими системами» [6]. В данной статье мы также будем следовать этой исходной предпосылке.

В российской научной литературе проблеме трансакционных издержек посвящено немало работ $[7,8,18]$, но с учетом специфики природопользования эта тематика представлена недостаточно и часто лишь опосредованно. Концептуальные основы для разработки исследовательских подходов в этой области заложены в работах Е.В. Рюминой $[19,20]$ и В. А. Крюкова [21], хотя они прямо не нацелены на изучение данных проблем.

Величина и характер трансакционных издержек во многом определяются институциональной средой в сфере природопользования. Работающие институты повышают эффективность природопользования как в экономическом, так и в экологическом плане; но надо отдавать себе отчет в том, что они «не приходят бесплатно» [6. С. 185], и «цену институтов» необходимо учитывать.

Экологические проблемы, возникающие вследствие возрастающей интенсивности природопользования, заставляют общество искать пути адаптации к изменяющимся условиям, предотвращения необратимых негативных последствий через сравнение различных вариантов институциональных решений [22. С. 254].

«Зависимость от колеи», т. е. от предыдущего пути развития и сложившихся трендов $[23,24]$, проявляется в том числе в эффектах «замкнутости», когда социоэкономическая система «замыкается» и «не впускает» новые технологические и институциональные парадигмы. И дело не только в том, 
что переключение на новые парадигмы и модели требует затрат. Часто знания и стиль мышления ключевых «игроков» заставляют их принимать решения в рамках существующих парадигм: «колея» формируется и в головах. Практические привычки, стиль жизни - это также источник «замкнутости» системы.

Эффект колеи проявляется также в институциональных провалах рынка [25]: институты, созданные для решения старых проблем, часто создают барьеры для решения новых. Например, в России повышение самостоятельности местных органов в расходовании муниципального бюджета (безусловно, имеющее определенные преимущества) нередко приводит к тому, что средства, поступающие в виде платы за негативное воздействие на окружающую среду, расходуются не на решение экологических задач, а на другие нужды.

Сфера природопользования обладает значительной инерцией, особенно это касается минерально-сырьевого сектора. Это обусловлено необходимостью масштабных инвестиций, сложностью технологий, оборудования, «привязкой» к конкретным территориям, зависимостью от других отраслей, кадрового потенциала и др. Дополнительные трансакционные издержки могут возникать из-за того, что господствующие институты оказывают «замыкающее» влияние на институциональную среду и тем самым затрудняют переход к новым, необходимость которых уже назрела вследствие развития социально-экономической системы и технологического прогресса.

\section{Классификация трансакционных издержек в управлении природными ресурсами}

В работе [26] предложено разделение трансакционных издержек на две категории: ex ante, т. е. возникающие до реализации проекта (инициативы, программы и др.), и ex post-сопровождающие его реализацию. В опубликованной позднее статье Мак-Канн и др. [15] разработана более детальная классификация. Г. Маршалл считает необходимым дополнить ее в части ex post классом издержек, возникающих вследствие высокой степени неопределенности, характерной для продолжительных природно-ресурсных проектов (изменение макроэкономических условий, непредсказуемость последствий воздействия на окружающую среду и т. п.) и необходимости адаптации к меняющейся институциональной среде [6]. Р. Челлен в статье, посвященной управлению водными ресурсами, обосновал целесообразность их разделения на статические и динамические [27]. Трансакционные издержки часто необходимо рассматривать в совокупности с издержками, связанными с изменениями институциональной среды, которые могут существенно сказываться на их величине. Эти связи отражены в таблице 1.

\section{Таблица 1. Виды трансакционных издержек (ТИ) и их роль} в управлении природными ресурсами $[6,26,27]$

Ex ante ТИ - исследования и информационное обеспечение; разработка проекта, подготовка документации; выдача/получение разрешительных документов, определяющих допустимое экологическое воздействие; заключение предварительных контрактов, их правовое сопровождение Ex post ТИ - управление проектом, мониторинг (технологический и экологический); заключение текущих контрактов, их правовое сопровождение; издержки «принуждения» для обеспечения выполнения экологических обязательств, включая судебные и административные; издержки, связанные с адаптацией к изменяющимся условиям в период выполнения проекта (технологическим, климатическим, экологическим, институциональным)

Статические ТИ (STC) - возникающие в рамках функционирования существующих институтов Динамические ТИ (ITC) - связанные с изменением институтов, переходом от прежних институциональных решений к новым

ТИ институциональной замкнутости (ILC) - дополнительные издержки, возникающие вследствие институциональной замкнутости и «зависимости от колеи»

ТИ технологической замкнутости (TLC) - дополнительные, возникающие вследствие технологической замкнутости и «зависимости от колеи»

Многие авторы подчеркивают важность учета трансакционных издержек институциональной замкнутости. Например, выбор правительством Австралии патерналистской практики регулирования землепользования создает препятствия для внедрения экономических и административных стимулов, направленных на экологизацию хозяйственной деятельности. Практика распределения водных ресурсов в бассейнах Мюррей-Дарлинг в Австралии, Колорадо - в США, Саскачеван-Нельсон - в Канаде ограничивает возможности для реформирования управления, основанного на экосистемном подходе [6, 28].

Трансакционные издержки целесообразно рассматривать вкупе с трансформационными, т. е. расходами, связанными с преобразованием материальных затрат в конечную продукцию [5]. Выделяются следующие их виды:

- статические трансформационные издержки (STFC), возникающие в процессе выбора технологического решения, адекватного 
существующим институтам (например, выбор проекта разработки месторождения, наиболее выгодного компании с точки зрения существующей системы налогов, экологических платежей, таможенных пошлин и т. д.);

- издержки технологических переходов (ТTC), связанные с изменением технологий под влиянием изменений институциональной среды (например, внедрение новых технологий очистки сбросов в водные объекты вследствие законодательного ужесточения природоохранных требований).

Эти суммарные издержки - трансакционные и трансформационные - необходимо учитывать при разработке экологоэкономической политики. Обращает на себя внимание то, что во многих работах вопросы эколого-экономического регулирования относятся к коллективным действиям: в традициях западной политической культуры речь идет о выборе решений общества по отношению к природным благам, которые являются общим достоянием.

\section{Проблемы «замкнутости» и принцип предосторожности}

Западные исследования, посвященные трансакционным издержкам в управлении природными ресурсами, всегда ориентированы на поиски инструментов выработки и поддержки решений. В процессах природопользования неизбежно проявляется неопределенность, и де-факто эти решения принимаются в условиях ограниченной рациональности действующих лиц. Если в отношении издержек типа STC, ITC, STFC, TTC в принципе могут быть разработаны методы количественной оценки, то издержки ILC и TLC на этапе разработки институциональных решений оценить практически невозможно. Однако именно эти факторы могут стать ключевыми для достижения успеха или провала задуманных реформ. Тем не менее для этих случаев тоже предлагаются алгоритмы поддержки решений $[6,29]$.

Предположим, что рассматривается вопрос о целесообразности принятия новых институциональных решений (А) или (В), при этом не исключается отказ от обоих. Процедура предусматривает два этапа. На первом для каждого варианта оценивается сумма

$$
\text { Stotal }=\text { STC }+ \text { ITC }+ \text { STFC }+ \text { TTC, }
$$

и в качестве приоритетного (№ 1) выбирается тот вариант, у которого эта величина меньше. Другому варианту присваивается № 2 .

На втором этапе производится эвристическая оценка в контексте возможности негативных последствий из-за технологической и/или институциональной замкнутости и составляется «матрица выбора». Если эксперты ожидают, что проблемы замкнутости для рассматриваемого варианта настолько серьезны, что потребуется высокий уровень издержек ILC и/или TLC, то в матрице эти издержки помещаются со знаком «-», если незначительны - то со знаком «+» (табл. 2). Если негативные последствия институциональной замкнутости считаются весьма вероятными для обоих вариантов, то рекомендуется временно отказаться от институциональных изменений, так как на данном этапе инновации преждевременны, и все усилия и затраты по их продвижению могут оказаться напрасными.

\begin{tabular}{|c|c|c|c|c|c|}
\hline & \multicolumn{5}{|c|}{ Вариант (В) } \\
\hline & $\begin{array}{c}\text { Комбинации усло- } \\
\text { вий технологической } \\
\text { и институциональной } \\
\text { замкнутости }\end{array}$ & $\begin{array}{l}+T L C \\
+I L C\end{array}$ & $\begin{array}{l}+T L C \\
-I L C\end{array}$ & $\begin{array}{l}-T L C \\
+I L C\end{array}$ & $\begin{array}{l}-T L C \\
-I L C\end{array}$ \\
\hline \multirow{4}{*}{$\begin{array}{l}\text { Вариант } \\
\text { (A) }\end{array}$} & $\begin{array}{l}+T L C \\
+I L C\end{array}$ & $\begin{array}{l}\text { Выбираем } \\
\text { вариант A }\end{array}$ & $\begin{array}{l}\text { Выбираем } \\
\text { вариант A }\end{array}$ & $\begin{array}{c}\text { Выбираем } \\
\text { вариант A }\end{array}$ & $\begin{array}{l}\text { Выбираем } \\
\text { вариант A }\end{array}$ \\
\hline & $\begin{array}{l}+T L C \\
-I L C \\
\end{array}$ & $\begin{array}{l}\text { Выбираем } \\
\text { вариант В }\end{array}$ & $\begin{array}{l}\text { Оставляем } \\
\text { status quo }\end{array}$ & $\begin{array}{l}\text { Оставляем } \\
\text { status quo }\end{array}$ & $\begin{array}{l}\text { Оставляем } \\
\text { status quo }\end{array}$ \\
\hline & $\begin{array}{l}-T L C \\
+I L C\end{array}$ & $\begin{array}{l}\text { Выбираем } \\
\text { вариант B }\end{array}$ & $\begin{array}{l}\text { Оставляем } \\
\text { status quo }\end{array}$ & $\begin{array}{l}\text { Оставляем } \\
\text { status quo }\end{array}$ & $\begin{array}{l}\text { Оставляем } \\
\text { status quo }\end{array}$ \\
\hline & $\begin{array}{l}-T L C \\
-I L C\end{array}$ & $\begin{array}{l}\text { Выбираем } \\
\text { вариант В }\end{array}$ & $\begin{array}{l}\text { Оставляем } \\
\text { status quo }\end{array}$ & $\begin{array}{l}\text { Оставляем } \\
\text { status quo }\end{array}$ & $\begin{array}{l}\text { Оставляем } \\
\text { status quo }\end{array}$ \\
\hline
\end{tabular}

Разумеется, отказ предполагается не навсегда, а до того момента, когда будут преодолены эффекты технологической и институциональной замкнутости. В первом случае это может быть, например, вследствие системной государственной поддержки для стимулирования внедрения новых технологий, повышения импортных пошлин, снижающих привлекательность устаревших, но дешевых импортных средств производства и т. д.

Примечательно, что в работах $[6,29]$ решение ничего не менять определяется как «применение принципа предосторожности». 
По-видимому, в этом проявляется понимание определенной опасности и/или бесперспективности преждевременных реформ в неподходящей институциональной среде [30].

В работе [6] описанный алгоритм используется для оценки двух вариантов изменения правил водопользования с целью сохранения экосистем бассейна Мюррей-Дарлинг в Австралии, где состояние речных долин подвергается серьезному негативному воздействию вследствие активного водопотребления. Автор приходит к выводу, что программа выкупа государством части земель в речных долинах и прекращения там сельскохозяйственного производства с учетом всех описанных выше критериев предпочтительнее, чем альтернативная программа совершенствования инфраструктуры, обеспечивающей водопотребление на этой территории.

\section{Формирование природно-ресурсной и экологической политики: «злые» \\ и «послушные» проблемы}

«Провалы рынка» в решении экологических проблем хорошо известны [31], однако вопрос о том, насколько экономические инструменты его «корректировки» могут быть эффективны при согласовании экологических и экономических интересов, до сих пор остается предметом дискуссий $[4,32]$. Большое количество работ так или иначе затрагивают вопросы формирования экологической политики с целью решения так называемых «трудных» (или «злых») экологических проблем (wicked problems) [33]. К ним относятся проблемы климатических изменений под влиянием антропогенных факторов, ответственности в случае распределенных источников загрязнений, истощения водных ресурсов, сохранения экологических функций и биоразнообразия и т. д. Их отличают от «послушных» проблем (tame problems), в которых легко определяются причинно-следственные связи, и, как правило, можно поставить задачу в рамках одной научной дисциплины и решать ее традиционными научными методами (например, задача очистки сточных вод с целью сокращения сбросов загрязняющих веществ в водные объекты, разработка технологий переработки отходов и экономического стимулирования этой деятельности и др.).
Трансакционные издержки в управлении природными ресурсами часто рассматриваются в соотношении с издержками на предотвращение либо устранение негативных экологических последствий и сохранение природных благ. Например, затраты на экологические согласования-оформления и платежи за выбросы и сбросы и/или установку очистного оборудования. Без этого сложно говорить о разумном уровне издержек. Надо сказать, что на первом месте стоит экологический эффект, а не задача минимизации трансакционных издержек [22. С. 254], что принципиально важно. То есть эффективность понимается как достижение поставленных целей (в том числе экологических), соответствующих приоритетам общества, с наименьшими (или просто приемлемыми) трансакционными издержками. Существует также понимание того, что в случае «трудных» проблем (обычно в условиях высокой степени неопределенности) часто бессмысленно ставить задачу поиска оптимальной стратегии, и приемлемость (реалистичность) является неплохим решением [22].

Трансакционные издержки можно разделить на те, которые несут коммерческие компании, и те, которые возлагаются на общество в целом в лице уполномоченных контролирующих и регулирующих органов. В западной литературе они называются общественными, тогда как в России - государственными. Результаты эмпирических исследований говорят о том, что эти издержки играют ключевую роль при разработке природноресурсной политики, особенно когда речь идёт о «трудных» проблемах. Они могут быть весьма значительными: например, в работе [15] отмечается, что их доля в затратах на разработку и реализацию политики регулирования в агропромышленном комплексе США достигает 30\%. В статье [16] проводится сравнение величины трансакционных издержек при использовании различных институциональных решений, направленных на снижение выбросов двуокиси углерода в атмосферу в транспортном секторе Австралии. Оказалось, что эти затраты, в зависимости от выбранного варианта регулирования, могут различаться почти втрое: от 2,5 до 7,2 долл. в расчете на одну тонну сокращения выбросов эквивалента $\mathrm{CO}_{2}$. Авторы приходят к выводу, что эффективные институты могут существенно снижать эти издержки, они способствуют также повышению результативности экономических механизмов регулирования. 
В западной литературе сложилась традиция трехуровневого (восходящего к работам Э. Остром [9]) или четырехуровневого анализа (в соответствии с концепцией Уильямсона [11]). У Э. Остром это конституциональный, уровень коллективного выбора и практический. Уильямсон выделяет следующие уровни: 1) уровень неформальных институтов; к ним относятся в том числе культура и традиции; 2) правовой; 3) государственного управления и инструментов регулирования; 4) ценовых/рыночных факторов.

Культура может оказывать очень сильное влияние на вовлечение граждан в жизнь общества, на их базовые ценности, уровень доверия в обществе, их представления о справедливости, отношение к тем природным активам, которые являются общественными ресурсами [34]. Все это в той или иной степени находит отражение в размерах и характере трансакционных издержек. Многие исследователи отмечают, что они тем ниже, чем выше уровень доверия в обществе. Базовые ценности оказывают влияние на процессы распространения передовых экологических технологий и практик, и в зависимости от этого данные издержки в управлении природными ресурсами могут быть выше или ниже. Отношение к правительству влияет на исполнение требований и принятие экологических ограничений. Неформальные институты (культура и религия) могут в разной степени и с разными последствиями воздействовать на институциональную среду в сфере природопользования, порождаемую формальными институтами.

Согласно О. Уильямсону, формальная институциональная среда включает в себя конституции, правовые системы, законы и политические стратегии. В работах его последователей, посвященных управлению природными ресурсами, предполагается наличие и стабильное функционирование надежной правовой системы, а также демократических форм государственного устройства, поэтому то, что получается в развитых странах, иногда нереализуемо в развивающихся. Л. Мак-Канн [15] считает, что необходимость учета разнообразных мнений означает более высокие издержки. Э. Остром отмечает, что для успешного регулирования использования природных ресурсов чрезвычайно важно наличие оперативных и низкозатратных механизмов разрешения повсеместно возникающих конфликтных ситуаций [10].

\section{Заключение: такие разные концепции...}

При обсуждении проблем трансакционных издержек в российском природопользовании первоочередное значение имеет вопрос о неоправданно высоких затратах, связанных с посредническими структурами и сложившейся контрактной практикой, особенно в сфере добычи и переработки нефти и газа. В большинстве развитых стран с обширным природно-ресурсным сектором этот вопрос не столь актуален из-за существующей институциональной среды, где рыночная конкуренция и качественное государственное регулирование обеспечивают возможность нахождения эффективных решений в режиме саморегулирования [11]. Тем не менее проблеме конфликта интересов и лоббирования с целью снижения природоохранных стандартов зарубежные ученые уделяют очень серьезное внимание. Одним из надежных способов «не упустить» их из виду является рассмотрение трансакционных издержек вместе с затратами на сокращение либо предотвращение негативного воздействия при разработке процедур принятия решений - именно здесь объективно заложены причины конфликтов. Кроме того, это полезно для нейтрализации возможных нежелательных последствий изменений природноресурсной политики. Реформы могут встретить сопротивление вследствие эффекта «колеи» или институциональной замкнутости и не дать желаемого эффекта.

Например, в России уровень и практика определения размеров платежей за воздействие на водные объекты при добыче россыпного золота не только не способствуют экологической модернизации этого вида деятельности, но даже не стимулируют соблюдение природоохранного законодательства [35].

На наш взгляд, особого внимания заслуживает концептуальный подход к регулированию отношений природы и общества, которого придерживаются западные исследователи, позиционирующие себя как представители направления Ecological Economics [36]. Первичной считается задача, сформулированная как результат общественного выбора: обеспечение экологических интересов общества. А вторичным является вопрос о снижении природоохранных затрат, т. е. суммы трансакционных издержек и расходов на устранение либо предотвращение негативных воздействий. При этом подразумевается, что будет получен 
экономический результат, приемлемый для инициаторов процесca, в том числе для инвесторов.

Цель снижения собственно трансакционных издержек при этом не ставится. Важно снижать совокупные затраты на достижение экологических целей - государство видит свою ответственность за то, чтобы согласование экологических и экономических интересов не стоило обществу неоправданно дорого. Иногда эти издержки, например, на усиление государственного контроля и регулярного мониторинга, необходимо увеличивать. При высоких тарифах за негативное воздействие на окружающую среду это заставит (и заставляет!) компании устанавливать природоохранное оборудование, вводить системы экологического менеджмента и т. п. Дополнительные затраты на исследования позволяют избежать необратимых изменений природных систем и разрушения экологических функций - эти последствия могут обойтись обществу очень дорого.

Вопрос о получении лучшего экономического результата обычно в этом контексте не обсуждается: предполагается, что это - задача бизнеса, государственное управление должно лишь обеспечить равные условия, некоррупционные процедуры, независимый суд для разрешения коммерческих споров, антимонопольное регулирование и др. Ряд авторов считает, что в этот список необходимо включить инструменты, стимулирующие инновации, в том числе экологические, которые не должны ограничиваться чисто экономическими мерами [25].

Эта концепция в значительной мере реализуется во многих странах ОЭСР, что стало результатом глубинных институциональных изменений и усилий гражданского общества, направленных на повышение экологической ответственности бизнеса и государства. По-видимому, изменения коснулись и самого глубокого уровня неформальных институтов. Можно говорить о том, что во второй половине XX в. сформировались новая экологическая культура и традиции (хотя уровни экологической ответственности, например в скандинавских странах и Южной Европе, неодинаковы).

Эколого-экономическая политика развивающихся стран основана на принципиально иной концепции: целью является максимизация экономического результата. При этом нельзя сказать, что органы управления игнорируют экологические цели, во многих странах существует природоохранное законодательство, и бизнесу предписывается выполнение установленных норм, но их соблюдение часто понимается как «согласование» определенных уровней негативного воздействия (выбросов в атмосферу, сбросов в водные объекты и др.) и внесение соответствующих платежей (штрафов). Природоохранные законы в переходных экономиках, как правило, несовершенны, уровень допустимых выбросов, тарифы и штрафы занижены из-за стремления максимизировать экономический результат. Поэтому даже соблюдение норм не гарантирует экологического благополучия. Кроме того, есть «трудные» («злые») проблемы, которые плохо регулируются экономическими инструментами.

Характерным примером является Китай: высокие темпы экономического роста требовали гораздо более жестких нормативов, но меры были приняты лишь на пороге экологической катастрофы. Однако ситуация кардинально меняется [37]. Здесь важно отметить и то, что в Китае не ограничиваются только правовым уровнем институциональных реформ. На наших глазах разворачивается грандиозная информационно-идеологическая кампания, цель которой - изменить культуру природопользования населения всей страны [38, 39].

Эта же модель, направленная на максимизацию экономического результата, в значительной степени реализуется и в России. Однако трансакционные издержки в управлении природными ресурсами и соответствующие проблемы институциональных трансформаций в нашей стране - это предмет отдельного обсуждения.

\section{Литература}

1. Garrick D., McCann L., Pennel J. Transaction costs and environmental policy: Taking stock, looking forward // Ecological Economics. - 2013. Vol. 88. - P. 182-184.

2. Coase R. H. The problem of social cost. 726 // Journal of Law and Economics, 1960. - № 3. - P. 1-44.

3. Бобылев С.Н., Захаров В. М. Экосистемные услуги и экономика. М.: ООО «Типография ЛЕВКО», Ин-т устойчивого развития /Центр экологической политики России, 2009. - 72 с.

4. Farley J. Ecosystem services: The economic debate//Ecosystem services. - 2012. - Vol.1. - P. 40-49.

5. Wallis J. J., North D. C. Measuring the Transaction Sector in the American Economy, 1870-1970 // In: Engerman S. L. and Gallman R. E. (eds). 
Long-term Factors in American Economic Growth. Univ. of Chicago Press. 1986. - P. 95-161.

6. Marshall G. Transaction costs, collective action and adaptation in managing complex social-ecological systems // Ecological Economics. 2013. - Vol. 88. - P. 185-194.

7. Литвинцева Г. П., Гахова Н.А. Динамика трансакционного сектора в экономике: как учил Д. Норт // Journal of Institutional Studies. - 2016. T. 8. - № 2. - C. 38-50.

8. Шаститко А. А. Новая институциональная экономическая теория. M.: ТЕИС, 2010. - 848 c.

9. Ostrom E. Coping with tragedies of the commons // Annual Review of Political Science. - 1999. - Vol. 2. - P. 493-535.

10. Ostrom E. A general framework for analyzing sustainability of socialecological systems // Science. - 2009. - Vol. 325. - P. 419-422.

11. Williamson O. E. Transaction cost economics: how it works; where it is headed // The Economist. - 1998. - Vol. 146 (3). - P. 23-58.

12. Coggan A., Whitten S. M., Bennett J. Influences of transaction costs in environmental policy // Ecological Economics. - 2010. - Vol. 69. - P. 1777-1784.

13. Garrick D., Whitten S., Coggan A. Understanding the evolution and performance of water markets and allocation policy: A transaction costs analysis framework // Ecological Economics. - 2013. - Vol. 88. - P. 195-205. 14. Krutilla K., Krause R. Transaction costs and environmental policy: an assessment framework and literature review. International Review of Environmental and Resource Economics. - 2010. - № 4. - P. 261-354. 15. McCann L., Colby B., Easter K. W., Kasterine A., Kuperan K. V. Transaction costs measurement for evaluating environmental policies // Ecological Economics. - 2005. - Vol. 52 (4). - P. 527-542.

16. Ofei-Mensah A., Bennett J. Transaction costs of alternative greenhouse gas policies in the Australian transport energy sector // Ecological Economics. - 2013. - Vol. 88. - P. 214-221.

17. Pannell D. J., Roberts A., Park G., Alexander J. Improving environmental decisions: A transaction cost story // Ecological Economics. - 2013. Vol. 88. - P. 244-252.

18. Комкова А. А., Шаститко А. Е. Количественная оценка трансакционного сектора: возможности, ограничения, результаты //Научные исследования экономического факультета. Эл. журнал. - 2014. - Т. 6. № 3. - C. 25-48.

19. Рюмина Е.В. Экологическая версия предназначения природной ренты//Экономическая наука современной России. - 2001. - № 2. C. 11-22.

20. Рюмина Е. В. Экономический ущерб от экологических правонарушений// Российская акад. наук, Ин-т проблем рынка. - М., 2009. Сер. Экономическая наука современной России.

21. Крюков В.А. Сырьевые территории в новой институциональной реальности// Пространственная экономика. - 2014. - № 4. - С. 26-60. 22. McCann L. Transaction costs and environmental policy design // Ecological Economics. - 2013. - Vol. 88. - P. 253-262.
23. Аузан А. А. «Эффект колеи». Проблема зависимости от траектории предшествующего развития - эволюция гипотезы //Вестник Москов ского университета. Серия 6: Экономика. - 2015. - № 1. - С. 3-17.

24. Нуреев Р. М. Россия после кризиса - эффект колеи // Journal of Institutional Studies. - 2010. - T. 2. - № 2. - C. 7-26.

25. Blueprints for an integration of science, technology and environmental policy (BLURPRINT). Mannheim. - ZEW. - 2004.

26. Hanna $S$. Efficiencies of user participation in natural resource management. In: Hanna, S., Munasinghe, M. (Eds.), Property Rights and the Environment: Social and Ecological Issues. Beijer International Institute of Ecological Economic and the World Bank. - Washington, 1995. D.C. P. 59-67.

27. Challen R. Institutions, Transaction Costs and Environmental Policy: Institutional Reform for Water Resources. Edward Elgar, Northampton, MA, 2000.

28. Heinmiller B. T. Path dependency and collective action in common pool governance // International Journal of the Commons. - 2009. - № 3 (1). P. 131-147.

29. Quiggin J. Uncertainty, awareness and the precautionary principle. Presentation to the Symposium on Progress and Problems in Measuring Sustainable Development. - 2008. - 4 Ap. University of Sydney (Online: http://sydney.edu.au/agriculture/documents/harris_symposium/Quiggin_precautionary0804.pdf).

30. Полтерович В.М. Элементы теории реформ. - М.: Экономика, 2007. - 447c.

31. Гирусов Э. В., Бобылев С. Н., Новоселов А. Л., Чепурных Н. В. Экология и экономика природопользования. - М.: Юнити, 1998.

32. Corbera E. Problematizing REDD+ as an experiment in payment for ecosystem services // Current options in Environmental sustainability. 2012. - Vol. 4. - P. 612-619.

33. Batie S. S. Wicked problems and applied economics // American Journal of Agricultural Economics. - 2008. - № 90 (5). - P. 1176-1191. 34. Vatn A. Institutions and The Environment. Edward Elgar Publishing. Chaltenham, UK, 2005. - $451 \mathrm{p}$

35. Глазырина И. П., Михеев И.Е., Элоян А. Ю. Экономика россыпного золота: доходы, трансакционные издержки и охрана природных систем // Материалы Всеросс. конф. с межд. участием «Эволюция биосферы и техногенез». - Чита, 2016. ИПРЭК СО РАН. - С. 25-28 [Эл. ресурс].

36. Daly H., Farley J. Ecological Economics: Principles and Applications. Washington: Island Press, 2003. - 450 p.

37. Забелина И.А., Клевакина Е.А. Экономическое развитие и негативное воздействие на окружающую среду в регионах трансграничного взаимодействия // ЭКО. - 2016. - № 8 (506). - С. 67-82.

38. URL: http://news.xinhuanet.com/politics/2015-05/05/c 1115187518. htm (дата обращения: 22.05.2015).

39. URL: http://m.russian.china.org.cn/russian/doc_1_26350_354805.html (дата обращения: 22.09.2016). 